\title{
Transcutaneous biopsy of adrenocortical carcinoma is rarely helpful in diagnosis, potentially harmful, but does not affect patient outcome
}

\author{
Andrew R Williams, Gary D Hammer ${ }^{1,+}$ and Tobias Else ${ }^{1}$ \\ University of Michigan Medical School, 1301 Catherine Street, Ann Arbor, Michigan 48109, USA and \\ ${ }^{1}$ Division of Metabolism, Endocrinology and Diabetes (MEND), Department of Internal Medicine, University of \\ Michigan Hospital and Health Systems, NI3 A17, 300 North Ingalls, Ann Arbor, Michigan 48109-5419, USA \\ ${ }^{\dagger}$ (G D Hammer is now at University of Michigan Medical School, 109 Zina Pitcher Place, 1528 BSRB, Ann Arbor, \\ Michigan 48109, USA)
}

\begin{abstract}
Context: Adrenocortical carcinoma (ACC) is a rare malignancy with high recurrence and mortality rates. The utility, sensitivity, and effect on patient outcome of transcutaneous adrenal biopsy (TAB) for single, large, adrenal masses are unclear.

Objective: This study evaluated the utility, diagnostic sensitivity, and effect on patient outcome of TAB in patients with ACC. Design and setting: We conducted a retrospective review of the electronic medical records of all ACC patients who were evaluated at the University of Michigan Health System from 1991 to 2011 . We evaluated the sensitivity of TAB for tumors with the final pathological diagnosis of ACC. We compared the characteristics and survival of patients with stage I-III disease who underwent TAB with those who did not undergo TAB.

Results: A total of 75 ACC patients with TAB were identified. Complications occurred in at least $11 \%$ of patients and were mainly associated with bleeding. The maximum sensitivity of the procedure in diagnosing ACC was $70 \%$. For stage I-III patients, baseline characteristics, stage at diagnosis, and adjuvant treatment with mitotane or radiation were not significantly different between the TAB $(n=36)$ and the non-TAB $(n=254)$ groups. There was no significant difference in recurrence-free $(P=0.7)$ or overall survival $(P=0.7)$ between patients who underwent TAB and those who did not. Conclusions: TAB of single, large, adrenal masses is usually unnecessary, exposes patients to risk, but does not affect recurrence-free or overall survival.
\end{abstract}

\section{Introduction}

Adrenal tumors are common and incidentally discovered in $1-2 \%$ of the population on cross-sectional imaging (1). Only a very small percentage of these are adrenocortical carcinomas (ACCs). An initial study reported a prevalence of ACC among incidentally found adrenal masses of $\sim 4 \%$ (2). A more recent review estimates the prevalence to be $1.4 \%$ (3). Nonetheless, ACC remains a clinical concern due to its dismal prognosis $(4,5)$. Symptoms are caused by either hormone excess or mass effect of the tumor.
Approximately $60 \%$ of patients present with evidence of adrenal steroid hormone excess. Approximately 30-50\% of ACCs are considered as 'non-functional' because they do not secrete hormones or they secrete mainly steroid hormone precursors. Tumor size is the most significant factor distinguishing benign from malignant adrenal masses. ACC has been identified in $2 \%$ of tumors smaller than $4 \mathrm{~cm}, 6 \%$ of tumors of $4.1-6 \mathrm{~cm}$, and $25 \%$ of tumors larger than $6 \mathrm{~cm}(6,7)$. 
There is a long-standing debate over the use of transcutaneous adrenal biopsy (TAB) in the setting of single, large, adrenal masses. Currently, the only widely accepted indication for an adrenal biopsy is a suspected metastasis from a known primary tumor in a patient for whom the result would change the therapeutic approach, e.g. surgery for limited disease vs chemotherapy for metastatic disease $(6,8)$. TAB should only be conducted after biochemical exclusion of a pheochromocytoma because of potentially fatal catecholamine surge during TAB $(6,9)$. Previous studies have shown that TAB is associated with a significant risk of morbidity and mortality $(10,11,12)$. Yet some patients with newly diagnosed single, large, adrenal masses without another primary cancer continue to undergo TABs.

It remains unclear whether this practice affects ACC patient outcome. The nature of $\mathrm{TAB}$ violates a fundamental principle of surgery on ACC, where en bloc resection is performed to avoid any violation of the tumor capsule (13). Indeed, there are cases in the literature reporting needle-track seeding associated with TAB of ACC and adrenal metastases $(14,15)$. In light of this, an understanding of the effect of $\mathrm{TAB}$ on patient outcome is important because it may shed light on whether $\mathrm{TAB}$ should be considered as a risk factor when deciding on adjuvant treatment after complete surgical excision. The two main adjuvant therapies employed are radiation therapy and pharmacotherapy with mitotane. Although most studies regarding adjuvant therapy are small and retrospective in nature, there is good evidence that radiation therapy prevents local recurrence and mitotane prolongs recurrence-free survival $(4,16,17,18,19)$.

The aim of our study was to evaluate the utility, sensitivity, and, most importantly, effect on patient outcome of $\mathrm{TAB}$ in a retrospective study of patients with the diagnosis of ACC and biopsy of an adrenal mass seen at the University of Michigan.

\section{Subjects and methods}

\section{Patient identification and review of medical records}

We used ICD-9 billing codes to query the University of Michigan Medical Center electronic medical records system to identify all patients who were evaluated for ACC at our institution over a 20-year period (1991-2011). Patient electronic medical records were reviewed individually and using a natural language processing algorithm for electronic medical records (EMERSE) (20). All cases had a confirmed diagnosis of ACC by pathological reports or in a small number of cases by adrenal hormone excess and a metastasized tumor with a large adrenal primary tumor. Data collected included: demographics, staging, hormone production, reason for biopsy, number of biopsies, institution performing the biopsy, complications associated with biopsy, pathology, adjuvant therapy, follow-up surgery, recurrence-free survival, and overall survival. All patients were staged based on the ENSAT staging system (21). For survival data, in addition to hospital medical records, we reviewed the Social Security Death Index.

\section{Categories of pathological diagnosis}

Pathological diagnoses of biopsy specimens were divided into five groups - 'ACC', 'benign', 'malignant', 'indeterminate', and 'nondiagnostic'. 'ACC' group signifies the pathological diagnosis of ACC. 'Benign' specimens include tissue interpreted as adrenal cortical adenoma, specimens containing normal or benign-appearing adrenal cortical cells, and specimens suggesting a cyst or myelolipoma. 'Malignant' group consists of specimens containing malignant cells not otherwise specified. 'Indeterminate' group consists of specimens interpreted as tissue of adrenal origin that could not be identified as benign or malignant. 'Nondiagnostic' group includes all other specimens deemed to be insufficient for a pathological diagnosis.

\section{Statistical analysis}

The endpoints selected for analysis were recurrence-free survival and overall survival. Recurrence-free survival was defined as the time from the date of surgical resection to the date of the earliest clinical evidence of recurrence of disease. Overall survival was defined as the time from the date of diagnosis to the date of death. In cases where patients did not reach the endpoint of survival times, they were censored according to the last follow-up date. Survival curves were plotted using the Kaplan-Meier method. Patients with a follow-up period less than the first event in a group were not included in analysis ( $<5 \%)$. Differences between subgroups were tested using the log-rank test. Survival was also analyzed using the univariable and multivariable Cox proportional hazards model, adjusting for age at diagnosis, sex, cortisol secretion, and adjuvant therapies. Multivariable analysis was then performed to look for independent predictors of survival. The $P$ values are reported and for interpretation a $P$ value of $<0.05$ was considered significant. Demographic and tumor characteristics were compared using the $\chi^{2}$-test or $t$-test for non-parametric and parametric parameters respectively. 
Table 1 Characteristics of all patients with adrenal tumor biopsies.

\begin{tabular}{|c|c|c|}
\hline Characteristics & $n=75$ & $\%$ \\
\hline \multicolumn{3}{|l|}{ Gender } \\
\hline Male & 35 & 47 \\
\hline Female & 40 & 53 \\
\hline \multicolumn{3}{|l|}{ Age at diagnosis } \\
\hline Median (years) & 51.9 & \\
\hline Range (years) & 17.1-77.3 & \\
\hline \multicolumn{3}{|l|}{ Race } \\
\hline Caucasian & 63 & 84 \\
\hline African American & 6 & 8 \\
\hline Asian & 2 & 3 \\
\hline Unknown & 4 & 5 \\
\hline \multicolumn{3}{|l|}{ Stage at diagnosis } \\
\hline I & 3 & 4 \\
\hline II & 22 & 29 \\
\hline III & 11 & 15 \\
\hline IV & 39 & 52 \\
\hline \multicolumn{3}{|l|}{ Hormone production } \\
\hline Any & 34 & 45 \\
\hline Cortisol & 29 & 39 \\
\hline Follow-up adrenalectomy & 56 & 75 \\
\hline
\end{tabular}

All data were analyzed using the Statistical Package for Social Sciences software, version 19.0 (SPSS, Inc.).

\section{Human subjects research approval}

All studies were approved by the University of Michigan Institutional Review Board (IRB). Initial data collection was carried out under an IRB application aiming to determine risk factors for ACC (HUM00045835). All participants of the study are part of the Michigan Endocrine Oncology Repository (HUM00024461).

\section{Results}

\section{Characteristics of patients with adrenal biopsy}

A total of 81 TABs were performed on 75 patients. Out of 75 patients, 69 had a single biopsy and six had two. There were 35 males (47\%) and 40 females (53\%). The median age at diagnosis was 51.9 years. The stage distribution was as follows: stage I, 3 (4\%); stage II, 22 (29\%); stage III, 11 (15\%); and stage IV, 39 (52\%). A total of 34 patients (45\%) had functional tumors based on clinical evaluation, and 29 patients (39\%) had cortisol-secreting tumors. All patients with stage I-III disease had a follow-up adrenalectomy, whereas 16 stage IV patients (41\%) underwent a follow-up adrenalectomy. The demographic and clinical characteristics of these patients are summarized in Table 1.

\section{Complications of adrenal tumor biopsies}

Of the total number of patients, eight (11\%) suffered TAB-related complications. However, documentation was not complete on all patients. Most complications were associated with bleeding during or after the procedure. One patient presented to the emergency department complaining of severe pain at the TAB site. One patient had a hemorrhage within the biopsied mass and became anemic. Four patients developed hematomas secondary to organ puncture: one in the lung, one in the left kidney, and two in the liver. In one case, puncture of the liver was associated with needle-track metastasis, which was diagnosed 2 years later. The patient underwent repeat surgery and is alive without evidence of disease. This patient was part of a previous study at our institution (14). One patient suffered a saddle pulmonary embolism shortly after undergoing biopsy and could not be anticoagulated due to the risk of bleeding from biopsy site. Subsequently, this patient died.

\section{Pathology diagnosis of adrenal tumor biopsies}

The histopathological findings for 75 biopsies are listed in Table 2. Of them, 66 (88\%) biopsies were performed at other institutions and nine (14\%) were nondiagnostic, not revealing a distinct pathological diagnosis. Of the biopsies where an adequate specimen was collected, 28 (42\%) were read as ACC, six (9\%) as malignant, six (9\%) as benign, and $17(26 \%)$ as indeterminate, meaning that they were deemed to be of adrenal origin, but no diagnosis regarding biological behavior could be made. Of the total 75 biopsies, $50(67 \%)$ were obtained at or available for review at the University of Michigan Pathology Department. The final diagnoses for biopsies read at the University of Michigan, including specimens from referred patients and specimens obtained at our institution, were as follows: ACC, 35 (70\%); malignant, seven (14\%); benign, one (2\%); indeterminate, one (2\%); and nondiagnostic, six (12\%).

Table 2 Pathological diagnosis for biopsies (read at other institutions or University of Michigan).

\begin{tabular}{|c|c|c|c|c|}
\hline & \multicolumn{2}{|c|}{ Other (66) } & \multicolumn{2}{|c|}{ University of Michigan (50) } \\
\hline & $n$ & $\%$ & $n$ & $\%$ \\
\hline ACC & 28 & 42 & 35 & 70 \\
\hline Malignant & 6 & 9 & 7 & 14 \\
\hline Benign & 6 & 9 & 1 & 2 \\
\hline Indeterminate & 17 & 26 & 1 & 2 \\
\hline Nondiagnostic & 9 & 14 & 6 & 12 \\
\hline
\end{tabular}


Table 3 Characteristics of patients with stage I-III tumors with and without biopsy.

\begin{tabular}{|c|c|c|c|c|c|}
\hline \multirow[b]{2}{*}{ Characteristics } & \multicolumn{2}{|c|}{ Biopsy $n=36$} & \multicolumn{2}{|c|}{ No biopsy $n=254$} & \multirow[b]{2}{*}{$\boldsymbol{P}$} \\
\hline & $n$ & $\%$ & $n$ & $\%$ & \\
\hline Gender & & & & & 1.0 \\
\hline Male & 13 & 36 & 94 & 37 & \\
\hline Female & 23 & 64 & 160 & 63 & \\
\hline Age at diagnosis & & & & & 0.052 \\
\hline Median (years) & 53 & & 46.4 & & \\
\hline Range (years) & $18.9-74.6$ & & $16-83.0$ & & \\
\hline Race & & & & & 0.65 \\
\hline Caucasian & 31 & 86 & 223 & 88 & \\
\hline African American & 2 & 6 & 9 & 4 & \\
\hline Asian & 0 & 0 & 7 & 3 & \\
\hline Unknown & 3 & 8 & 15 & 6 & \\
\hline Stage at diagnosis & & & & & 0.31 \\
\hline 1 & 3 & 8 & 9 & 4 & \\
\hline II & 22 & 61 & 147 & 58 & \\
\hline III & 11 & 31 & 98 & 39 & \\
\hline \multicolumn{6}{|c|}{ Hormone production } \\
\hline Any & 10 & 28 & 150 & 59 & 0.004 \\
\hline Cortisol & 9 & 25 & 108 & 43 & 0.048 \\
\hline \multicolumn{6}{|l|}{ Adjuvant mitotane } \\
\hline Yes & 10 & 28 & 95 & 37 & 0.08 \\
\hline Recommended $^{a}$ & 2 & 6 & 20 & 8 & \\
\hline No & 23 & 64 & 136 & 54 & \\
\hline Unknown & 1 & 3 & 3 & 1 & \\
\hline \multicolumn{6}{|l|}{ Adjuvant radiation } \\
\hline Yes & 7 & 19 & 52 & 21 & 0.17 \\
\hline Recommended $^{a}$ & 0 & 0 & 10 & 4 & \\
\hline No & 27 & 75 & 189 & 74 & \\
\hline Unknown & 2 & 6 & 3 & 1 & \\
\hline
\end{tabular}

${ }^{\mathrm{a}}$ Treatment recommended but not documented in patient's chart.

\section{Outcome of patients with stage I-III ACC and adrenal tumor biopsy}

In order to evaluate the effect of TAB on patient outcome, we analyzed all patients with non-metastasized ACC separately, excluding all stage IV patients. We compared patients with stage I-III disease who underwent TAB (36 patients) with patients with stage I-III disease who did not undergo TAB (242 patients). Patient characteristics are summarized in Table 3 . The only significant differences were observed regarding hormone production. In the TAB group, ten patients (28\%) had functional tumors, of whom nine secreted cortisol (25\%), as opposed to 150 patients (59\%) with functional tumors, of whom 108 patients (43\%) had cortisol-secreting tumors.

There was no significant difference in overall survival between patients who underwent $\mathrm{TAB}$ as part of their diagnostic work-up at any institution and those who did not (Kaplan-Meier, log-rank $P=0.7$; Fig. 1). The median survival for those who underwent TAB was 44 months
(s.E.M., 5.0) compared with 55 months (s.E.M., 8.0) for patients who did not undergo TAB. Nor was there a significant difference in recurrence-free survival between patients who underwent $\mathrm{TAB}$ as part of their diagnostic work-up and those who did not (Kaplan-Meier, log-rank $P=0.7$; Fig. 1A). The median recurrence-free survival time for those who underwent TAB was 14.9 months (s.E.M., 2.2), compared with 15.0 months (s.E.M., 1.7) for patients who did not undergo TAB (Kaplan-Meier, log-rank $P=0.6$; Fig. 1B). In addition, in univariable and multivariable analysis, adjusting for age at diagnosis, cortisol secretion, tumor stage, and adjuvant therapy, a history of a TAB did not show significant differences regarding overall survival or recurrence-free survival (Table 4).

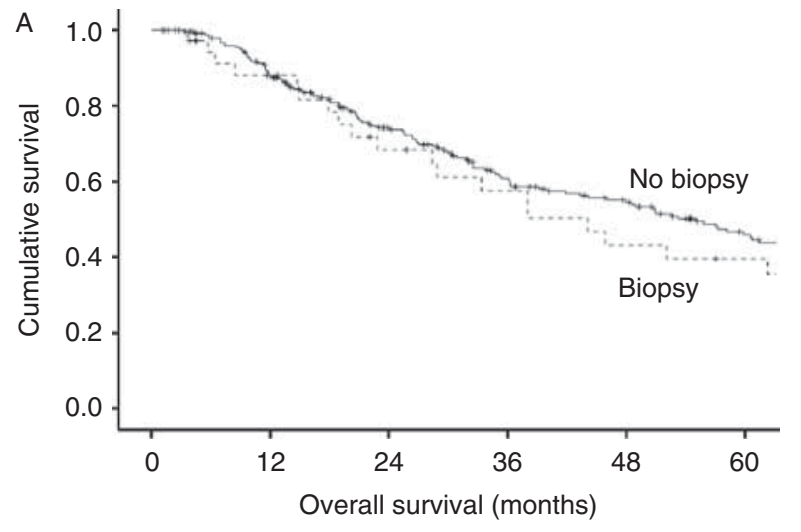

$\begin{array}{lllllll}\text { Biopsy } & 36 & 28 & 20 & 16 & 12 & 0 \\ \text { No biopsy } & 248 & 208 & 152 & 111 & 91 & 65\end{array}$

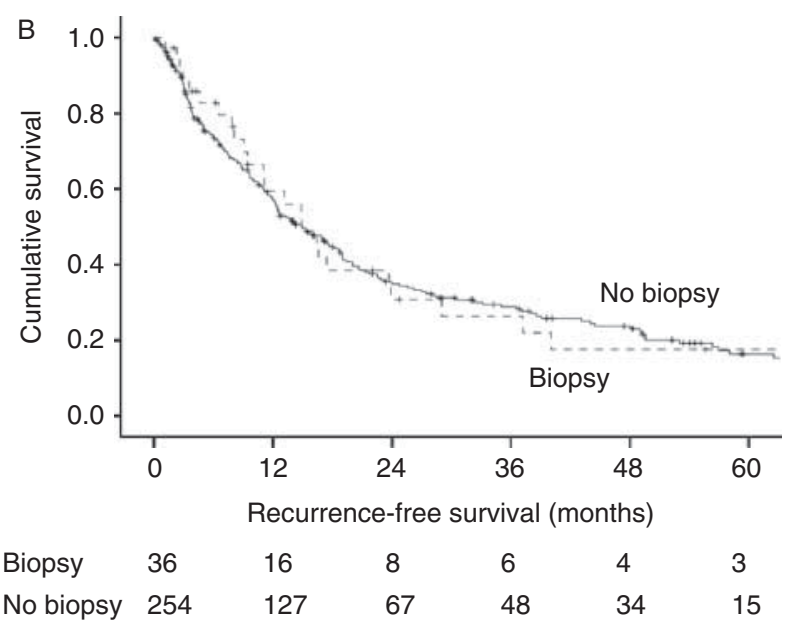

Figure 1

Kaplan-Meier plots for overall survival $(A)$ and recurrence-free survival (B). 
Table 4 Hazard ratios (HR) from Cox regression models, univariable and multivariable, including age at diagnosis, sex, and cortisol production, with and without inclusion of adjuvant therapies. HR for death for the variable biopsy vs no biopsy.

\begin{tabular}{|c|c|c|c|c|}
\hline \multirow[b]{2}{*}{ Adjustment } & \multicolumn{2}{|c|}{ Overall survival } & \multicolumn{2}{|c|}{$\begin{array}{l}\text { Recurrence-free } \\
\text { survival }\end{array}$} \\
\hline & $\mathrm{HR}$ & $P$ & $H R$ & $P$ \\
\hline Univariable & $1.1(0.7-1.8)$ & 0.6 & $0.9(0.6-1.4)$ & 0.7 \\
\hline $\begin{array}{l}\text { Age, sex, cortisol, } \\
\text { stage }\end{array}$ & $1.2(0.8-2.0)$ & 0.4 & $1.1(0.7-1.7)$ & 0.7 \\
\hline + mitotane & $1.2(0.7-1.9)$ & 0.5 & $1.0(0.7-1.7)$ & 0.7 \\
\hline$+\mathrm{XRT}$ & $1.2(0.8-1.9)$ & 0.4 & $1.1(0.7-1.7)$ & 0.7 \\
\hline + mitotane/XRT & $1.2(0.7-1.9)$ & 0.5 & $1.1(0.7-1.7)$ & 0.7 \\
\hline
\end{tabular}

\section{Discussion}

In summary, our data indicate that $\mathrm{TAB}$ has a low diagnostic sensitivity, is often unnecessary, exposes the patients to unnecessary risk, but does not change overall or recurrence-free survival.

There are serious risks associated with TAB. Multiple studies have investigated the complications stemming from this procedure $(14,15,22,23,24,25,26,27,28,29$, $30,31,32,33,34,35,36,37)$. Complication rates ranged from 0 to $12 \%$. Most of these studies involved small numbers of patients, making it difficult to assess the true complication rate. However, there are three studies that examined larger numbers of patients. Welch et al. (36) reviewed the results of 277 TABs and reported a rate of major complications of $2.8 \%$. The other two studies, with 83 and 97 patients, included all complications and described rates of 8.4 and $9 \%$ respectively $(14,33)$. These rates are slightly lower, but comparable with our results, which showed a complication rate of at least $11 \%$.

These rates are significant given the severity of the complications involved. The most frequently reported complications associated with TAB are hemorrhage (23, $31,33,35)$, pneumothorax $(24,28,33)$, pancreatitis (27), and isolated reports of adrenal abscess (29), bacteremia (23), and needle-tract metastasis (15). We identified one case of needle-track metastasis, which has previously been reported (15). This occurred in a case where the adrenal was biopsied via an unusual transhepatic approach. While we were unable to review follow-up imaging for needletrack seeding in all patients, the overall risk of needle-track metastasis seems to be low, but present. Moreover, in our study, TAB indirectly led to the death of one patient.

A feasibility study demonstrated that a high degree of accuracy is possible in the pathological evaluation of TAB samples obtained via an ex vivo approach (38).
The sensitivity in that study was $76.2 \%$. This is in accordance with the maximum sensitivity of $79.5 \%$ for the pathological diagnosis of ACC in our study, when taking into account only samples reviewed at the University of Michigan and disregarding inadequate samples. It is worthwhile to point out that this number clearly indicates the 'best-case scenario'. There is a clear limitation of a retrospective study conducted at a referral center, where biopsy and final specimen are often reviewed at the same time. The sensitivity of TAB is significantly lower in clinical practice taking into account that the review of samples was often conducted after the final surgical or biochemical diagnosis of ACC had been established. We found that the sensitivity of TAB, which takes into account the procedure of obtaining the biopsy as well as the pathological diagnosis, was at best $70 \%$. In our study, samples were regarded as sufficient for pathological diagnosis in $88 \%$ of the cases reviewed at our institution, which agrees with previously reported adequacy ratings ranging from 67 to $100 \%(22,23,25,28,33$, $37,39,40,41)$. In terms of diagnosing malignant disease, but not necessarily establishing the diagnosis of ACC, the sensitivity of $\mathrm{TAB}$ increases to $84 \%$. However, it is concerning that some malignant lesions were read as benign, particularly by non-endocrine pathologists. In selected cases, there is the option of evaluating adrenal lesions with an FDG-PET, which has good diagnostic parameters for benign and malignant adrenocortical tumors (42).

In our study, only 38 (51\%) of the TABs were conducted on stage IV ACCs, where evaluation of an adrenal mass as a potential metastasis is regarded as useful with the benefit of the procedure probably outweighing the risk. In this setting, 84\% sensitivity in diagnosing an ACC as a malignant adrenal lesion might be helpful in further patient management. However, TAB was unnecessary in a large proportion (49\%) of patients in this study, where evaluating for a metastatic tumor was not the primary goal. Moreover, $46 \%$ of all patients and $28 \%$ of stage I-III patients had clinical or biochemical evidence of hormone production, making a diagnosis other than an adrenal neoplasm unlikely. This is in agreement with a previous study that showed that hormonal work-up is often incomplete in ACC patients (43). Recent studies using urine steroid metabolite analysis may even further increase the sensitivity and specificity of non-invasive biochemical diagnostics (44). Furthermore, TAB in the setting of adrenal tumors with suspicion for malignancy due to size or imaging criteria is seldom helpful as these lesions are almost invariably treated surgically. The only 
very rare exception to this rule is when an adrenal tumor is clinically strongly suspected to be a non-adrenocortical tumor that requires a therapy other than surgery, such as an adrenal lymphoma. In these cases, biopsy and specimen staining for adrenocortical-specific markers, such as SF1 or inhibin A, might be particularly helpful (45).

However, TAB does not change recurrence-free or overall survival. This is particularly important when assessing a patient's risk of recurrence and deciding on adjuvant treatment. In this study, no significant differences were found in overall or recurrence-free survival between patient groups with stage I-III disease with and without a history of biopsy. The use of adjuvant treatments in both groups was not significantly different nor were the survival parameters even after adjusting for the main risk factors and post-surgical therapies. Therefore, $\mathrm{TAB}$ does not significantly impact survival and should not be a major consideration when planning adjuvant therapies, such as mitotane or radiation.

Overall, we conclude that TAB may be useful in the setting of a metastasis from an unknown primary tumor for diagnosing ACC with sufficient sensitivity. However, in cases of single, large, adrenal masses, TAB should be avoided. TAB might be regarded as relatively safe if used in the right setting, but it still poses an unnecessary risk to the patient considering its paltry diagnostic gain and irrelevance in making future therapeutic decisions. Thorough biochemical work-up can identify the majority of these tumors as adrenocortical in origin. Moreover, surgery is the mainstay of therapy for any tumor with suspicion for malignancy confined to the adrenal gland. However, TAB does not significantly affect patient outcome and the history of a TAB should not majorly affect adjuvant therapeutic decisions.

\section{Declaration of interest}

The authors declare that there is no conflict of interest that could be perceived as prejudicing the impartiality of the research reported.

Funding

T Else was sponsored by the National Institutes of Health (grant number T32-DK007245).

\section{Author contribution statement}

A Williams conducted data gathering, data analysis, interpretation, and manuscript writing and participated in study design. G D Hammer participated in study design, result interpretation, and manuscript writing. T Else participated in data gathering, and conducted data analysis, result interpretation, manuscript writing, and study design.

\section{References}

1 Mansmann G, Lau J, Balk E, Rothberg M, Miyachi Y \& Bornstein SR. The clinically inapparent adrenal mass: update in diagnosis and management. Endocrine Reviews 200425 309-340. (doi:10.1210/er.2002-0031)

2 Mantero F, Terzolo M, Arnaldi G, Osella G, Masini AM, Ali A, Giovagnetti M, Opocher G \& Angeli A. A survey on adrenal incidentaloma in Italy. Study Group on Adrenal Tumors of the Italian Society of Endocrinology. Journal of Clinical Endocrinology and Metabolism 200085 637-644.

3 Cawood TJ, Hunt PJ, O'Shea D, Cole D \& Soule S. Recommended evaluation of adrenal incidentalomas is costly, has high false-positive rates and confers a risk of fatal cancer that is similar to the risk of the adrenal lesion becoming malignant; time for a rethink? European Journal of Endocrinology 2009161 513-527. (doi:10.1530/EJE-09-0234)

4 Else T, Williams AR, Sabolch A, Jolly S, Miller BS \& Hammer GD. Adjuvant therapies and patient and tumor characteristics associated with survival of adult patients with adrenocortical carcinoma. Journal of Clinical Endocrinology and Metabolism 201499 455-461. (doi:10.1210/ jc.2013-2856)

5 Fassnacht M, Kroiss M \& Allolio B. Update in adrenocortical carcinoma. Journal of Clinical Endocrinology and Metabolism 201398 4551-4564. (doi:10.1210/jc.2013-3020)

6 Schteingart DE, Doherty GM, Gauger PG, Giordano TJ, Hammer GD, Korobkin M \& Worden FP. Management of patients with adrenal cancer: recommendations of an international consensus conference. Endocrine-Related Cancer 200512 667-680. (doi:10.1677/erc.1.01029)

7 Grumbach MM, Biller BM, Braunstein GD, Campbell KK, Carney JA, Godley PA, Harris EL, Lee JK, Oertel YC, Posner MC et al. Management of the clinically inapparent adrenal mass ("incidentaloma"). Annals of Internal Medicine 2003138 424-429. (doi:10.7326/0003-4819-138-5-200303040-00013)

8 Fassnacht M \& Allolio B. Clinical management of adrenocortical carcinoma. Best Practice \& Research. Clinical Endocrinology \& Metabolism 200923 273-289. (doi:10.1016/j.beem.2008.10.008)

9 Vanderveen KA, Thompson SM, Callstrom MR, Young WF Jr, Grant CS Farley DR, Richards ML \& Thompson GB. Biopsy of pheochromocytomas and paragangliomas: potential for disaster. Surgery 2009146 1158-1166. (doi:10.1016/j.surg.2009.09.013)

10 Kloos RT, Gross MD, Francis IR, Korobkin M \& Shapiro B. Incidentally discovered adrenal masses. Endocrine Reviews 199516 460-484.

11 Quayle FJ, Spitler JA, Pierce RA, Lairmore TC, Moley JF \& Brunt LM. Needle biopsy of incidentally discovered adrenal masses is rarely informative and potentially hazardous. Surgery 2007142 497-502 discussion 502-4. (doi:10.1016/j.surg.2007.07.013)

12 Terzolo M, Stigliano A, Chiodini I, Loli P, Furlani L, Arnaldi G, Reimondo G, Pia A, Toscano V, Zini M et al. AME position statement on adrenal incidentaloma. European Journal of Endocrinology 2011164 851-870. (doi:10.1530/EJE-10-1147)

13 Miller BS, Ammori JB, Gauger PG, Broome JT, Hammer GD \& Doherty GM. Laparoscopic resection is inappropriate in patients with known or suspected adrenocortical carcinoma. World Journal of Surgery 201034 1380-1385. (doi:10.1007/s00268-010-0532-2)

14 Mody MK, Kazerooni EA \& Korobkin M. Percutaneous CT-guided biopsy of adrenal masses: immediate and delayed complications. Journal of Computer Assisted Tomography 199519 434-439. (doi:10.1097/00004728-199505000-00017)

15 Habscheid W, Pfeiffer M, Demmrich J \& Muller HA. Puncture track metastasis after ultrasound-guided fine-needle puncture biopsy. A rare complication? Deutsche Medizinische Wochenschrift 1990115 212-215. (doi:10.1055/s-2008-1064995)

16 Terzolo M, Angeli A, Fassnacht M, Daffara F, Tauchmanova L, Conton PA, Rossetto R, Buci L, Sperone P, Grossrubatscher E et al. Adjuvant mitotane treatment for adrenocortical carcinoma. New England Journal of Medicine 2007356 2372-2380. (doi:10.1056/ NEJMoa063360) 
17 Sabolch A, Feng M, Griffith K, Hammer G, Doherty G \& Ben-Josef E. Adjuvant and definitive radiotherapy for adrenocortical carcinoma. International Journal of Radiation Oncology, Biology, Physics $2010 \mathbf{8 0}$ 1477-1484. (doi:10.1016/j.ijrobp.2010.04.030)

18 Fassnacht M, Hahner S, Polat B, Koschker AC, Kenn W, Flentje M \& Allolio B. Efficacy of adjuvant radiotherapy of the tumor bed on local recurrence of adrenocortical carcinoma. Journal of Clinical Endocrinology and Metabolism 200691 4501-4504. (doi:10.1210/jc.2006-1007)

19 Polat B, Fassnacht M, Pfreundner L, Guckenberger M, Bratengeier K, Johanssen S, Kenn W, Hahner S, Allolio B \& Flentje M. Radiotherapy in adrenocortical carcinoma. Cancer 2009115 2816-2823. (doi:10.1002/ cncr.24331)

20 Hanauer DA. EMERSE: The Electronic Medical Record Search Engine. AMIA Annual Symposium Proceedings 20062006941.

21 Fassnacht M, Johanssen S, Quinkler M, Bucsky P, Willenberg HS, Beuschlein F, Terzolo M, Mueller HH, Hahner S \& Allolio B. Limited prognostic value of the 2004 International Union Against Cancer staging classification for adrenocortical carcinoma: proposal for a Revised TNM Classification. Cancer 2009115 243-250. (doi:10.1002/cncr.24030)

22 Berkman WA, Bernardino ME, Sewell CW, Price RB \& Sones PJ Jr. The computed tomography-guided adrenal biopsy. An alternative to surgery in adrenal mass diagnosis. Cancer 198453 2098-2103. (doi:10.1002/1097-0142(19840515)53:10<2098::AID-CNCR2820 $531018>3.0 . \mathrm{CO} ; 2-0)$

23 Bernardino ME, Walther MM, Phillips VM, Graham SD Jr, Sewell CW, Gedgaudas-McClees K, Baumgartner BR, Torres WE \& Erwin BC. CT-guided adrenal biopsy: accuracy, safety, and indications. AJR. American Journal of Roentgenology 1985144 67-69. (doi:10.2214/ ajr.144.1.67)

24 Ferrucci JT Jr, Wittenberg J, Mueller PR, Simeone JF, Harbin WP, Kirkpatrick RH \& Taft PD. Diagnosis of abdominal malignancy by radiologic fine-needle aspiration biopsy. AJR. American Journal of Roentgenology 1980134 323-330. (doi:10.2214/ajr.134.2.323)

25 Heaston DK, Handel DB, Ashton PR \& Korobkin M. Narrow gauge needle aspiration of solid adrenal masses. AJR. American Journal of Roentgenology 1982138 1143-1148. (doi:10.2214/ajr.138.6.1143)

26 Heiberg E \& Wolverson MK. Ipsilateral decubitus position for percutaneous CT-guided adrenal biopsy. Journal of Computer Assisted Tomography 19859 217-218. (doi:10.1097/00004728198501000-00044)

27 Kane NM, Korobkin M, Francis IR, Quint LE \& Cascade PN. Percutaneous biopsy of left adrenal masses: prevalence of pancreatitis after anterior approach. AJR. American Journal of Roentgenology 1991157 777-780. (doi:10.2214/ajr.157.4.1892034)

28 Katz RL, Patel S, Mackay B \& Zornoza J. Fine needle aspiration cytology of the adrenal gland. Acta Cytologica 198428 269-282.

29 Masmiquel L, Hernandez-Pascual C, Simo R \& Mesa J. Adrenal abscess as a complication of adrenal fine-needle biopsy. American Journal of Medicine 199395 244-245. (doi:10.1016/0002-9343(93)90269-U)

30 Montali G, Solbiati L, Bossi MC, De Pra L, Di Donna A \& Ravetto C. Sonographically guided fine-needle aspiration biopsy of adrenal masses. AJR. American Journal of Roentgenology 1984143 1081-1084. (doi:10.2214/ajr.143.5.1081)

31 Pagani JJ. Non-small cell lung carcinoma adrenal metastases. Computed tomography and percutaneous needle biopsy in their diagnosis. Cancer 198453 1058-1060. (doi:10.1002/1097-0142 (19840301)53:5 < 1058::AID-CNCR2820530507> 3.0.CO;2-N)

32 Price RB, Bernardino ME, Berkman WA, Sones PJ Jr \& Torres WE. Biopsy of the right adrenal gland by the transhepatic approach. Radiology 1983 148566.

33 Silverman SG, Mueller PR, Pinkney LP, Koenker RM \& Seltzer SE. Predictive value of image-guided adrenal biopsy: analysis of results of 101 biopsies. Radiology 1993187 715-718.

34 vanSonnenberg E, Wittenberg J, Ferrucci JT Jr, Mueller PR \& Simeone JF. Triangulation method for percutaneous needle guidance: the angled approach to upper abdominal masses. AJR. American Journal of Roentgenology 1981137 757-761. (doi:10.2214/ajr.137.4.757)

35 Welch TJ, Sheedy PF II, Johnson CD, Johnson CM \& Stephens DH. CT-guided biopsy: prospective analysis of 1,000 procedures. Radiology 1989171 493-496.

36 Welch TJ, Sheedy PF II, Stephens DH, Johnson CM \& Swensen SJ. Percutaneous adrenal biopsy: review of a 10-year experience. Radiology 1994193 341-344.

37 Zornoza J, Ordonez N, Bernardino ME \& Cohen MA. Percutaneous biopsy of adrenal tumors. Urology 198118 412-416. (doi:10.1016/ 0090-4295(81)90407-6)

38 Saeger W, Fassnacht M, Chita R, Prager G, Nies C, Lorenz K, Barlehner E, Simon D, Niederle B, Beuschlein F et al. High diagnostic accuracy of adrenal core biopsy: results of the German and Austrian adrenal network multicenter trial in 220 consecutive patients. Human Pathology 200334 180-186. (doi:10.1053/hupa.2003.24)

39 Karstrup S, Torp-Pedersen S, Nolsoe C, Horn T \& Hegedus L. Ultrasonically guided fine-needle biopsies from adrenal tumors. Scandinavian Journal of Urology and Nephrology. Supplementum 1991137 $31-34$.

40 Tikkakoski T, Taavitsainen M, Paivansalo M, Lahde S \& ApajaSarkkinen M. Accuracy of adrenal biopsy guided by ultrasound and CT. Acta Radiologica 199132 371-374. (doi:10.3109/02841859109177587)

41 Wadih GE, Nance KV \& Silverman JF. Fine-needle aspiration cytology of the adrenal gland. Fifty biopsies in 48 patients. Archives of Pathology \& Laboratory Medicine 1992116 841-846.

42 Groussin L, Bonardel G, Silvera S, Tissier F, Coste J, Abiven G, Libe R, Bienvenu M, Alberini JL, Salenave $\mathrm{S}$ et al. ${ }^{18} \mathrm{~F}$-fluorodeoxyglucose positron emission tomography for the diagnosis of adrenocortical tumors: a prospective study in 77 operated patients. Journal of Clinical Endocrinology and Metabolism 200994 1713-1722. (doi:10.1210/ jc.2008-2302)

43 Johanssen S, Hahner S, Saeger W, Quinkler M, Beuschlein F, Dralle H, Haaf M, Kroiss M, Jurowich C, Langer P et al. Deficits in the management of patients with adrenocortical carcinoma in Germany. Deutsches Ärzteblatt International 2010107 885-891.

44 Arlt W, Biehl M, Taylor AE, Hahner S, Libe R, Hughes BA, Schneider P, Smith DJ, Stiekema H, Krone $\mathrm{N}$ et al. Urine steroid metabolomics as a biomarker tool for detecting malignancy in adrenal tumors. Journal of Clinical Endocrinology and Metabolism 201196 3775-3784. (doi:10.1210/ jc.2011-1565)

45 Sbiera S, Schmull S, Assie G, Voelker HU, Kraus L, Beyer M, Ragazzon B, Beuschlein F, Willenberg HS, Hahner S et al. High diagnostic and prognostic value of steroidogenic factor-1 expression in adrenal tumors. Journal of Clinical Endocrinology and Metabolism 201095 E161-E171. (doi:10.1210/jc.2010-0653)

Received 16 December 2013

Revised version received 17 February 2014

Accepted 13 March 2014 